\title{
Measuring integration in new countries of immigration
}

\author{
Coșciug Anatolie ${ }^{1 *}$
}

${ }^{1}$ Lucian Blaga University of Sibiu, Department of Sociology and Social Work, 2A Lucian Blaga, 550169 Sibiu, Romania.

KEYWORDS

Immigrant integration

Emerging immigrant destinations

Immigration in Romania

Intra-European

migration

Refugee integration

Third Country Nationals integration

\section{ABSTRACT}

The purpose of this study is to develop a framework to measure immigrant integration in emerging immigrant destinations. After several decades of intensive research, the definition and assessment of immigrants' integration remains elusive. Increasingly more attempts have been made to foster scientific progress in the field in the las decades. Yet, immigrant integration in emerging destination countries remains particularly little studied despite several calls for more research on the topic. The developed integration framework (i.e. the Integration Score) is composed of 6 dimensions and 24 indicators of integration (4 indicators for every dimension). To empirically test the validity and internal consistency of the Integration Score, this article uses unique data collected as part of the Romanian Immigrant Integration Index (IIIR) research project consisting of a sample of 645 immigrant respondents from Romania. The empirical tests prove the validity and internal consistency of the proposed integration framework. The implications of this study are that a gap in the literature was addressed and this can play a key role in better understanding immigrant integration by offering a different view on how integration unfolds in societies with minimal institutional support.

\footnotetext{
${ }^{*}$ Contact address: anatolie.cosciug@ulbsibiu.ro (A. Coșciug)
} 


\section{Introduction}

This study addresses one of the fundamental challenges faced by researchers in migration studies: how to define and measure immigrant integration. With increasing levels of migration in many countries around the globe, immigrants' successful integration into the host countries has remained one of the main topics of debate in migration scholarship (OECD/EU 2015; Ager and Strang 2008a; Schinkel 2018; Bauböck and Tripkovic 2017). Especially in the context of destination countries diversification, many questions were again raised in relation to immigrants' integration. Among them, the most pressing ones were about the pressure on social and educational services, the rise of far right and xenophobic social movements, the burden put on the destination countries which had previously little experience with immigrant integration, or the needs migrants have during the integration process. As some scholars have suggested, the study of immigrant integration has tried but partially failed to provide definitive answers to these questions due to, among other issues, the lack of common understanding and measure of immigrants' integration (Puma, Lichtenstein, and Stein 2018; Harder et al. 2018; Bauböck and Tripkovic 2017).

This lack of shared understanding on the ways to measure immigrant integration is especially surprising considering the fact that numerous attempts have been made and significant resources have been deployed in the last several decades to analyse and monitor the integration of immigrants in destination societies (Beversluis et al. 2017). Most of these studies on immigration integration were conducted in North America (e.g. the USA and Canada) and Western European countries, such as Great Britain, Germany, France, and other (Schneider and Crul 2010; Ager and Strang 2008a; Schinkel 2018; Bauböck and Tripkovic 2017; Garcés-Mascareñas and Penninx 2016; Loch 2014). While considerable effort is put to research immigrant integration in 'traditional' destination countries, research has also begun to be carried out lately, albeit encountering numerous barriers, on the topic of immigrant integration in emerging immigrant destinations, i.e. countries where immigration has expanded exponentially over the past few years (OECD/EU 2018, 2015).

Informed by this phenomenon of increasing immigration towards new destinations, this article is concerned with the study of immigrant integration 
in emerging destinations. One important reason for this endeavour is the lack of studies on the topic of immigrant integration in emerging destinations using quantitative data collected from immigrants. In the new immigrant destinations the foreign population is rapidly increasing but still has a small presence in the overall population and tend to have an 'unusual' pattern of settlement (Messina and Williamson 2014). In this context, gathering data about the immigrant population in the emerging destinations is difficult, and as a consequence, most of the existing studies tend to work with secondary data or with what experts or the local population believe about immigrants' integration rather than working with data collected directly from the immigrant population. Another important reason is that to study immigrant integration in new destinations can be fruitful to provide an empirical base for public policies in emerging destinations which too often lack this kind of support. One more important reason is that studying immigrant integration in emerging destinations can help improving existent understanding of immigrant integration by offering a different view on how integration unfolds in societies with minimal institutional support. Additionally, studying immigrant integration can also test if and how the proposed definitions and ways to capture immigrants' integration, developed in countries with long traditions of immigration, can be translated to the context of emerging destinations.

Romania, like many of its neighbours, it still predominantly a country of emigration but it is increasingly dependent on a significant influx of immigrants to further develop economically and compensate for a shrinking population caused by emigration and aging (Cos,ciug et al. 2018). Using Romania as an emerging destination, this study provides scholars and other interested stakeholders with an integration framework which was empirically tested for validity and internal consistency using quantitative data collected directly from the immigrants. 


\section{Literature review}

\subsection{Immigrant integration. Working definition and assessment}

After several decades of intensive research and despite significant effort, a consensus on how to define and measure immigrant integration is still lacking (Schinkel 2018; Messina and Williamson 2014; Saharso 2019). Ager and Strang (2008b) or Penninx (2019) but other authors as well (Schneider and Crul 2010; Castles et al. 2002) correctly pointed out the confusion surrounding the concept of immigrant integration, coining it as a 'chaotic concept', which in other words means a buzzword used by many but with different meanings. Many studies simply avoid using or proposing a definition of the term. Other studies mention the complex nature of the term, others cite its complex nature and wide use in both research and policy, thus explaining this lack of a common understanding of the term (Puma, Lichtenstein, and Stein 2018; Harder et al. 2018; Bauböck and Tripkovic 2017).

However, two definitions seem to be accepted most often in migration scholarship. One, in which integration is as a two-way process of becoming an accepted part of society (Garcés-Mascareñas and Penninx 2016; Bijl and Verweij 2012; Council of Europe 1997). The second refers to immigrant integration as the process through which immigrants come to the same status as the native-born (Schneider and Crul 2010; Messina and Williamson 2014; OECD/EU 2018; Aleksynska and Algan 2010; Jimenez 2011). However, these definitions spark many criticisms which can be resumed in the following 5 categories: i) they are too wide/ambiguous and leave space for interpretation; ii) they do not define the dimensions through which comparison with the native population should be done; iii) the fact that they are normative and assume that immigrants should assimilate into de destination country; iv) that to use the nation-state as a unit of analysis is problematic from a transnational perspective; v) or that the policy influences how integration is researched (Schneider and Crul 2010; Puma, Lichtenstein, and Stein 2018; Messina and Williamson 2014; Favell 2003; Loch 2014; Saharso 2019; Faist 2000; Klarenbeek 2019; Abdou 2019).

In the last few years, increasingly more attempts have been made to foster scientific progress in the field by proposing a definition and standardized method of assessment of immigrants' integration with varying 
degrees of success. One of the relatively successful efforts to overcome the criticisms associated with the previously used definitions is the work of Harder and colleagues (2018). Their framework defines immigrant integration as the 'degree to which immigrants have the knowledge and capacity to build a successful, fulfilling life in the host society' (Harder et al. 2018: 11484). This definition has two important aspects: knowledge and capacity. The knowledge aspect of integration covers both immigrants' fluency in the destination country's language(s) and other foreign languages, and their ability to have the necessary knowledge to navigate various institutional settings. The capacity aspect of integration includes the various forms of resources that migrants possess (e.g. social, economic, etc.). As in many other studies, (Huddleston, Niessen, and Tjaden 2013; Ager and Strang 2008a; OECD/EU 2015, 2018; Huddleston et al. 20 15; Drăgan et al. 2014)2 ${ }^{2}$ Harder and his colleagues use 6 dimensions to measure immigrant integration. The psychological dimension refers to the sense of belonging (e.g. their connection with the host society), the economic dimension includes areas such as income and employment, the political dimension captures the political and civic participation, the social aspect seizes the social ties, the linguistic one measures the ability to use the local language, and the navigational one refers to the management of the basic needs in the host country. As in other studies, Harder and his colleagues use a number of indictors which together are clustered in a integration dimension (OECD/EU 2015, 2018; Huddleston et al. 2015; Harder et al. 2018; Puma, Lichtenstein, and Stein 2018). Their 12 items scale is the short version and a 24 items scale is the long version, with 2 and respectively 4 indicators asked for each of the 6 areas of integration ${ }^{3}$.

\footnotetext{
2 For instance, (Ager and Strang 2008b) propose 10 domains of immigrant integration: employment, housing, education, health, citizenship and rights (clustered as markers and means), followed by social bridges, social bonds, and social links (clustered as social connections), than language and cultural knowledge, safety and stability (as facilitators), and finally rights and citizenship (foundation). The list of Zaragoza indicators were also clustered in 5 dimensions: employment, education, social inclusion, active citizenship and welcoming society (Huddleston, Niessen, and Tjaden 2013) while the 'Settling In' study by (OECD/EU 2015) uses labour market, job quality, training, income, housing, health status, civic engagement and social cohesion.

3 As an example, (OECD/EU 2015) uses 27 indicators (such as types of contracts, working hours, involuntary part-time, overqualification rate, share of self-employment, etc.) organized around five areas of integration. The Zaragoza list is composed of 21 indicators in the comprehensive form and 46 in the extend form (e.g. employment, education social inclusion, active citizenship welcoming society, employment rate, highest educational attainment, unemployment rate tertiary attainment, at-risk-ofpoverty, etc.) (Huddleston, Niessen, and Tjaden 2013).
} 
2.2 Defining and measuring immigrant integration in emerging destination countries

This framework developed by Harder et al. (2018) has been chosen as a reference in this study for several reasons. First, it is one of few immigrant integration frameworks that was empirically tested. Second, compared to other models, this framework conceptualizes integration using both behavioural and psychological items. Third, this integration model was developed in order to be applied in various contexts, not only in 'traditional' destinations in Western Europe and North America. However, while choosing this integration model could partially help with the problem of how to define immigrant integration in the emerging destination, it does not make up for the scarcity of studies on emerging immigrant destinations, particularly literature which is empirical based, collects data directly from immigrants or uses collected empirical evidences to test or improve the proposed definitions of integration. The lack of this kind of empirically driven research in emerging destinations hinders efforts to identify key factors that could be used by emerging destinations (which typically have limited experience in integrating migrants) to promote integration.

To study immigrant integration in new destinations can be fruitful beyond the obvious reason of providing an empirical base for public policies in emerging destinations. As Grzymała-Kazłowska (2015: 461) pointedly argue when speaking about Poland, an emerging destination in Central and Eastern Europe, studying immigrant integration in emerging destinations can help improving existent understanding of immigrant integration by offering a different view on how integration unfolds in societies with minimal institutional support:

'This makes research on the integration of immigrants in Poland particularly interesting, the more so as it shows the processes and mechanisms of adaptation occurring in a situation of minimal institutional support, so they can be examined from a different perspective from that possible in Western societies.' 
But the existent scholarship cannot help too much in these endeavours as not so many studies were interested in if and how immigrants integrate in emerging destinations. For instance, the research carried out by Drbohlav and Dzúrová (2007: 71-72) directly highlights this situation when speaking about research on immigrant integration in emerging destinations in general but also referring to the case of Czech Republic in particular:

'there is not too much at this moment the new immigration countries $\{\ldots\}$ could rely on when designing their migration and integration policies and practices $\{\ldots\}$. Concerning research activities, whereas rather descriptive, or if analytical, very simple, quantitative or qualitative studies in the given field have so far prevailed.'

Similar findings about the lack of empirical driven studies were reported in several other studies. For instance, the prominent report conducted in the context of the National Integration Evaluation Mechanism project (NIEM 2019: 32) which involved looking at a number of emerging and traditional destinations in Europe and it planned to compare them. However, this endeavour could not be successfully pursued due to the lack of data:

'Through their pervasive character, the current data gaps render a systematic and meaningful comparison across countries with regard to a large number of indicators impossible. Given the limited access to and availability of data, currently, only three out of the six building blocks of a comprehensive approach can be comparatively assessed:'

Another similar example is the report published by OECD/EU (2018: 30). The report refers to the topic of immigrant integration in the OECD/EU/G20 countries and distinguish among several types of immigrant destination. What seems to be particular to the emerging destinations is the lack of reliable data:

'The last group of immigrant destinations [i.e. emerging destinations] includes a very diverse set of OECD countries from the Americas, Asia, and Europe. In all of them, less than 3\% of the 
population is foreign-born. As a result, information on integration outcomes is often not available and where it is - as for employment - there are relatively wide variations.'

Alongside the above examples, an extensive literature search confirmed the dearth of quantitative studies based on data collected directly from immigrants in emerging destinations. Nearly all studies, although revealing, were based on policy evaluation, secondary sources and experts or local population perception about immigrants integration rather than working with data collected directly from immigrants (Huddleston et al. 2015; Voicu et al. 2015b, 2015a; Migration Policy Group/Institute of Public Affairs 2019; Stefańska 2015; Bijl and Verweij 2012; OECD/EU 2015, 2018; Schlueter, Meuleman, and Davidov 2013; Garcés-Mascareñas and Penninx 2016; Bauböck and Tripkovic 2017). It goes without saying that these approaches have many valid points to make using these types of data. However, there are many aspects regarding immigrant integration which can be analysed only by working quantitative data collected directly from immigrants.

There are a handful of exceptions, nevertheless. Grzymała-Kazłowska (2015) uses a sample of 169 Vietnamese and 162 Ukrainian immigrants living in the Warsaw area in Poland to discuss their adaptation strategies. The author concludes that there is a dissimilarity between the adaptation strategies used by the two groups: Ukrainians tend to accumulate bridging capital with the Polish society while the Vietnamese tend to accumulate the bonding capital but also to generate status-bridging capital. Drbohlav and Dzúrová (2007) work with a non-probability sample formed of 126 immigrants living in Prague to assess the models of inclusion into the Czech society. One of the main findings of this research is that the Ukrainian immigrants are transnationally involved, Vietnamese migrants tend to live in separated communities, and Armenians tend to practice an assimilation strategy. OECD/EU (2018) report works with secondary quantitative and qualitative data to document the immigrant integration outcomes in the EU, OECD and G20 countries. The report discusses on various indicators, such as the so called "Zaragoza indicators', to provide one of the few international comparisons of immigrants' integration outcomes for various types of immigrant destinations. 
However, even these studies dealing with the topic of immigrant integration in emerging destinations working with data collected directly from immigrants tend to use the same definitions and frameworks developed in traditional destinations without critically discussing or empirically assessing their applicability to the emerging destinations. As Messina and Williamson (2014: 10-11) have accurately argued in their article, the meaning and history of the term 'immigrant integrating' as it was developed in traditional destinations will 'likely influence the policy and political response of new immigrant destination' and, as it is argued in this article, certainly does influence the way immigrant integration is researched in emerging destinations.

\subsection{Defining and measuring immigrant integration in Romania, an emerging destination}

Romania, an emerging destination in the CEE region, is no exception in respect to the dearth of studies where the proposed integration frameworks are empirically tested. Its joining of the European Union in 2007 was a moment that marked the start of a series of important changes for the Romanian society. Some of them have been extensively studied, such as the process of democratic consolidation, emigration or re-industrialization (Levitz and Pop-Eleches 2010; Rusu 2008; King and Sum 2011), while other processes of arguably equal relevance have not found their place on the public or research agendas. Such an example, less studied but with great potential to generate major changes in Romanian society, is the international immigration to Romania. One of the main reasons is probably that Romania is traditionally seen as an emigration country. According to the latest estimates, some 3 to 4 million people left the country in the last 3 decades, and one third of the population lived at least once outside the country for more than 6 months (Anghel et al. 2016; Coșciug 2019; Croitoru, Sandu, and Tudor 2014: 7).

With around 380.000 foreign born people living now in Romania, the country is rapidly becoming an important immigration destination in the CEE region (OECD/EU 2018; United Nations 2017). The process was particularly accelerated in the recent years. According to the United Nations (2017) report, in 2005 the proportion of immigrants living in Romania was about $0.5 \%$ of the total population. This proportion increased 4 times in 12 years, up to about 
2\% in 2017 of the total population of about 19.5 million (EUROSTAT 2019). But the growth was not uniform distributed across the migrant categories. One of the visible increases was in the number of beneficiaries of international protection. For example, 3924 persons with a form of international protection were registered in 2017, an increase of about 30 \% compared with 2016. Another important but smaller increase is in the amount of EU/EEA citizens which has increased by about 3\% from 2017 to 2018. Similarly, yearly increases of around 3\% can also be seen for the category of third country nationals (TCNs), which, for example, also grew by around 3\% from 2016 to 62926 people in 2017 (Cosciug et al. 2018)§. Even so, these three categories of immigrants taken together account for only one third of the approximately 380,000 immigrants living in Romania. The remaining two thirds of immigrants, and the category of immigrants with the highest annual growth, are actually made up of migrants from different countries, mostly from the CEE region, who claimed Romanian ancestry and acquired Romanian citizenship. This category of people includes: a) Romanian ethnics who live in the historical communities around Romania in countries like Republic of Moldova, Ukraine, Serbia, and so on and acquire the Romanian citizenship; b) offspring of the Romanian citizens living abroad who acquire the Romanian citizenship (Cos,ciug et al. 2018; OECD/EU 2018).

\section{Methods}

\subsection{The development of a theoretical model of Immigrant integration}

Considering the substantial debates surrounding the definition and understanding of immigrant integration in general and the lack of previous studies dealing with this topic in the case emerging destinations, this study undertakes in the first phase a review of the literature on how immigrant integration is defined and measured. As such, the most important question in conducting the literature review was to understand how the concept of immigrant integration was defined in other studies and how it was measured.

\footnotetext{
$\S$ Earlier reliable data on the number of immigrants by category could not be identified.
} 
The review covered national, European and international research studies, research projects, reports, acts and norms, books and scientific articles and it resulted in a list of definitions, dimensions and indicators appearing in the documents consulted as relevant for the immigrant integration. This list also includes information about the source and type of research in which the indicators appear, how they have been defined and conceptualized and measured, the arguments why it is important to use that specific aspect in assessing the integration of immigrants, the studies in which they are used, the scoring rule (if any) and any other additional data that can help to better understand those indicators. Thus, the list consisted of about 350 indicators that were used in various studies, research and public policies to analyse the integration of migrants. A full description of the consulted studies and the results can be consulted in the research report of the Romanian Immigrant Integration Index (IIIR) research project (Cos,ciug et al. 2018).

This initial list of indicators has gone through 3 verification and validation processes. First, interviews and focus groups with immigrants living in Romania were organized to discuss the understanding of integration indicators and whether they capture all relevant aspects of their migration and integration experience. Second, only those indicators for which data could be gathered through the resources available to IIIR research project were considered from the initial list of integration indicators. Third, a series of meetings and consultations were organized with public institutions, NGOs, and researchers who have experience with the topic of immigrant integration generally or with the indicators considered for this research project more specifically. Discussions were held regarding if and how well these indicators capture the specificities of the Romanian legislation and practices, the socioeconomic peculiarities of migrants living in Romania, and the viability of public institutions supporting future data collection initiatives on immigration and integration. At the end of the process, all these indicators were checked by the research teams from a methodological point of view (e.g. constructing validity and clear directionality, applicability across regional environments and various immigrant groups).

The process detailed above has led to propose a theoretical model of immigrant integration based on 6 dimensions of integration: dispositional, linguistic, economic, civic, social and contextual. Dispositional integration 
captures the sense of belonging, immigrants' future plans and their perception of discrimination and discrimination instances. The linguistic integration includes questions about the language spoken at work or school, the one used when at home or with family, the language used during free time or with friends, and attendance of Romanian Language Classes. The economic integration captures the respondent's household income, if the respondent is economically active, if certain types of social benefits were obtained, and the share of household income on basic expenses. Civic integration includes questions about citizenship acquisition, membership in political parties, NGOs membership and whether they are part of professional associations or unions. Social integration considers at the immigrant's association membership, if the people visiting their houses are Romanian citizens, if the neighbourhood is composed of Romanians, and if their family includes Romanians. The aspect of contextual integration captures if respondents are currently involved in education/training programs, the social distance indicator, immigrants' health status and the household quality.

Once the theoretical framework was developed, a scoring rule was created. For each of the 4 items which compose a dimension, a score of 0 (absence) and 1 (presence) was given. As an example, in the linguistic dimension if a respondent uses the Romanian language at work or school (indicator number $5)$, it was noted with a value of 1 while for the opposite situation the value of 0 was given. As such, for each dimension, the maximum score was 4 while the minimum was 0 . For any given respondent, a score between 0 and 24 could be assigned as an overall Integration Score. 
Table 1: Six Dimensions of Immigrant Integration and Corresponding Indicators

\begin{tabular}{ll}
\hline Dimension & Indicator \\
\hline I. Dispositional & 1. Sense of belonging to the town/region/country \\
& 2. Future plans to stay in Romania \\
& 3. Lack of discrimination perception \\
& 4. Lack of discrimination instances \\
5. Use of RL at work/school & 6. Use of RL at home/family \\
7. Linguistic & 8. RL class enrolment \\
9. Income level above national average & 10. Economically active \\
1II. Economic & 12. Household expenses \\
& 13. Citizenship acquisition \\
14. Member in PP \\
15. Member in NGOs \\
16. Member in Unions/PA \\
17. Romanians in the associations' membership \\
18.Visit by Romanians \\
19. Romanians in neighbourhood \\
20. Romanians in family \\
21. Currently in education/training in Romania \\
22. Good health status \\
23. Social distance \\
24. Good household quality \\
VI. Contextual
\end{tabular}

\subsection{Data collection}

This article uses data obtained in the Romanian Immigrant Integration Index (IIIR) research project (Cos,ciug et al. 2018). As part of the overall project, a survey was conducted between October and December 2018 by the Romanian Centre for Comparative Migration Research. The survey consisted of two types of items: core items $(n=24)$, which were scored according to the above matrix and which could contribute to the final Integration Score (IS), and auxiliary items $(n=40)$ which were not scored and did not contribute to the IS 
but provided supplementary information about factors related to integration. According to the complexity of the items included in the immigrant integration framework, one or several questions were formulated in the survey for each item.

The drafted survey was discussed in 4 focus groups with immigrants living in Romania, researchers with background in migration studies, public officials working in institutions interested in the topic of immigrant integration, and representatives of various international and national/local associations. The resulting questionnaire was piloted in Cluj-Napoca with the participants at the one of Romanian Language classes.

Collecting data on immigrant population in emerging destinations is a difficult task given the fact that the proportion of immigrants in the total population is very low and the access to immigrants of different professional backgrounds and countries of origin is very difficult. This is why we encountered difficulties while applying methods used elsewhere, such as using the telephone book or home addresses (Ersanilli and Koopmans 2013; Wachter and Fleischmann 2018; Harder et al. 2018; McKenzie and Mistiaen 2009). Thus, what studies in emerging destinations may do is first, to identify areas with relatively large proportions of immigrants and to multiply data collection efforts in those areas through the 'snowball' sample (Drbohlav and Dzúrová 2007; Reichel and Morales 2017; Lindstrom 2016). A similar approach has been used in the IIIR research project where questionnaires were applied in specific locations with a higher presence of immigrants (refugee accommodation centres, universities, NGOs, immigration offices, places of worship, job centres, etc.).

In order to increase the immigrant's propensity to take part in the research, two methods were employed. First, the questionnaire was translated from Romanian into 5 other international languages spoken by Romanian immigrants - Turkish, Arabic, French, English and Italian. The translations were done by the members of the IIIR project research team who were proficient in these languages and the translations were validated with the help of immigrants living in the Cluj area. Second, the questionnaire could be completed both face-to-face with the help of the trained questionnaire operators and also online following the www.iiir.ro/chestionar-imigranti link. 


\section{Results}

\subsection{Testing the construct validity of the developed immigrants' integration framework}

A test or any given concept is considered valid if it measures what it purports to measure (Borsboom, Mellenbergh, and Van Heerden 2004). Several methods can be employed to test the construct validity of a given concept or test (Smith 2005). One of the most common ways to do so in migration scholarship is to check whether the proposed measure correlates with predictors previously identified in the literature as having an association with integration level (Harder et al. 2018; Brown, Peri, and Ruebelt 2011; Beversluis et al. 2017).

In spite of the debates on precise meanings of immigrants' integration, there is an agreement of a number of variables describing it. One such example is the years of residency in the destination country. For instance in the OECD/EU $(2015,2018)$ studies highlighted that the longer the period an immigrant lives in a country the better the chances of being integrated in that society. Similar findings were reported in several other studies as well (Wachter and Fleischmann 2018; Huddleston, Niessen, and Tjaden 2013; Harder et al. 2018; OECD/EU 2018; Beversluis et al. 2017; Bauböck and Tripkovic 2017). Another accepted predictor of immigrant integration level is related to education, in the sense that the more highly educated an immigrant is, the more capable they will be of quickly and effectively integrating in the destination society (Maria de Paola; Giorgio Brunello 2016; Huddleston, Niessen, and Tjaden 2013; OECD/EU 2015, 2018). A third important predictor on which wide agreement exists is the legal status of the immigrants, in the sense that the various legal statuses and the legal rights it they entail can hinder or foster integration. As an example of this, Harder and the colleagues (2018) finds for instance that immigrant with temporary visa have lower integration scores comparing with the permanent residents or the naturalized ones. Another example is the report by OECD/EU (2018: 223) where it is highlighted that Third Country Nationals tend to have worst integration outcomes comparing with the EU migrants or the local population. Similar findings were reported in several other studies, such as (Drbohlav and Dzúrová 2007) or Da Lomba (2010). 
In this research the validity of the proposed measure for immigrant integration will be tested using three independent variables: years of residency, if the respondents have higher education or not and the legal status; and two control variables: age and gender. In migration scholarship, the variables of age and gender, as with number of years of residency, legal status and education, are widely accepted as important control/mediating variables (OECD/EU 2018, 2015; Huddleston, Niessen, and Tjaden 2013; Lichtenstein and Puma 2018; Puma, Lichtenstein, and Stein 2018).

In this research, the years of residency were counted in two different forms: a) for respondents born in Romania, the years of residency were based on their year of birth minus the time (if any) spent in previous migration experiences outside Romania; b) for respondents born outside Romania, there was a specifically designed question asking about the time they have lived in Romania. For the second variable, higher education was coded as a dummy variable where the value 1 was given to those who have university education or higher while other respondents were given the value 0 . The legal status variable was constructed as a dummy where respondents with Romanian or other EU member state citizenship where assigned with the value 1 while the refugees and TCNs with the value of 0 . This distinction was made considering that Romania is part of EU and legally speaking the EU state member citizens enjoy the same rights as the Romanian citizens while TCNs and refugees have a number of rights limited (e.g. political and associative rights, etc.). The control variables age and gender were inquired upon with specifically designed questions in the questionnaire. The gender variable has been transformed into a dummy variable where the female respondents were assigned the value 1 and the male respondents were assigned with the value 0 . The age was measured asking about respondents' year of birth. 
Table 2: Full multiple linear regression output for coefficient plots

\begin{tabular}{|c|c|}
\hline & Integration Score (IS) \\
\hline Years of residency & $0.069 *$ \\
\hline Education (University) & $2.345 * * *$ \\
\hline Legal status (EU/Ro citizen) & -0.429 \\
\hline Female respondent & $0.711 *$ \\
\hline Age & 0.033 \\
\hline Constant & -56.306 \\
\hline Observations & 645 \\
\hline R2 & 0.099 \\
\hline Adjusted R2 & 0.092 \\
\hline Residual Std. Error $(\mathrm{df}=596)$ & 17.720 \\
\hline F Statistic $(\mathrm{df}=5 ; 591)$ & $13.007 * * *$ \\
\hline
\end{tabular}

Note: $* \mathrm{p}<0.05 ; * * \mathrm{p}<0.01 ; * * * \mathrm{p}<0.001$

Table 2 provides a nuanced perspective on how the overall Integration Score correlates with well-established predictors of immigrant integration. To test this, a multiple linear regression was completed using the R software. The Integration Score is conditionally correlated with two predictors - years of residency and education - in the expected direction while the correlation with the legal status variable is not in the expected direction. To illustrate this, an increase of one year of the independent variable years of residency is associated with an 0.069-point increase in the Integration Score, controlling for the other variables $(P$ value $<0.05)$. Similar findings are reported in the case of the higher education independent variable where the respondents with higher education have an Integration Score with 2.345 points higher in average compared with respondent with less than higher education (the reference category), controlling for the other independent variables effect $(\mathrm{P}$ value $<0.05)$. In the case of the legal status, the respondents with EU/CEE member states or Romanian citizenship have an integration score lower with 0.429 points in average comparing with Third Country Nationals and refugees, controlling for the other independent variables effect ( $\mathrm{P}$ value $>0.05$ ). In the case of the first control variables, female respondents have, on average, higher integration scores with 0.711 points compared with male respondents ( $\mathrm{P}$ value $<0.05$ ), controlling for other variables. In the case of the second control variable, an increase of one year in the age is associated with an increase of 
0.033 points in the integration score $(\mathrm{P}$ value $>0.05)$, controlling for other variables.

As exemplified above, the result of the multiple linear regression shows that the Integration Score correlates with two theoretically identified variables - education and years of residency - in the expected direction while the third independent variable - legal status - has an unexpected negative correlation while controlling for the effect of two other variables. The results suggest that the Integration Score accurately measures immigrant integration since higher levels of integration can be observed, as expected, for the immigrants with higher education and longer residency in the destination country. The unexpected negative correlation of the Integration Score with the immigrants' legal status can be seen as an illustrative example of how integration unfolds in societies with minimal institutional support. As such, to have access to the same legal rights as the local population does not automatically transpose in a better integration outcome in societies where the institutions have little experience in integrating migrants and the institutional support is minimal.

\subsection{Testing the internal consistency of the developed immigrants' integration model}

As in the case of the construct validity, there are also several ways to measure the internal consistency of a given concept. One of the most common ways to test the extent to which all of the items of a test measure the same latent variable is to use Cronbach's alpha. In other words, Cronbach's alpha measures whether scores on similar items are related (internally consistent). Cronbach's alpha is in fact a conservative lower bound estimator of instrument reliability (OECD 2008). Testing for internal consistency using Cronbach's alpha is also widely used in studies within migration scholarship in general and in studies on immigrant integration specifically (Roots, Masso, and Ainsaar 2016; Beversluis et al. 2017; Lindstrom 2016). The latent construct of interest in this research was the Integration Score. As such, the internal consistency was examined for the IS variable ( $\mathrm{N}=6$ dimensions). The value of the Cronbach's alpha coefficient $(\alpha=0.732)$ calculated for the 6 dimensions of integration which compose the immigrant integration framework used in this study indicates that the dimensions were related to each other and that the dimensions were not completely redundant in the information they contribute to the Integration Score. In other words, each dimension 
contributed with unique information to the measurement of the Integration Score construct, which is what was desired considering that each dimension was designed to bring additional information on immigrants' integration. This result is also important considering that it can empirically contribute to the literature where integration is understood as multidimensional concept (Phalet and Swyngedouw 2003; Harder et al. 2018).

Another widespread method in social and migration studies used to test for internal consistency in the case of concepts composed of several dimensions is through the assessment of the correlation between the dimensions which compose the main concept (convergent and divergent). Convergent validity uses correlations to measure constructs that theoretically are expected to be related to each other, while divergent validity measure constructs that should not be theoretically related. In other words, theoretically similar constructs should have stronger correlations while the constructs dissimilar should have weaker correlations (Puma, Lichtenstein, and Stein 2018; Beversluis et al. 2017). Figure 1 shows the pairwise relationship and correlation between the 6 dimensions which compose the Integration Score which was performed using the $\mathrm{R}$ software. The six dimensions of integration are positively correlated, indicating that immigrants who score higher on one dimension also tend to score high on the other dimensions.

With that said, it can be observed that some relationships are rather weak. For example, the civic integration and linguistic dimensions of integration are only weakly correlated $(\mathrm{r}=0.16)$. Other low correlations are between economic and linguistic dimensions $(r=0.22)$, or between linguistic and contextual integration or the contextual and social integration $(r=0.24)$. Higher correlations are between contextual and dispositional $(r=0.45)$, linguistic and dispositional $(r=0.44)$ and contextual and economic $(r=0.41)$. All the correlations are statistically significant at a $\mathrm{p}$ value lower than 0.001 and $N=645$. The findings are in accordance with the literature where constructs which are similar (such as dispositional and linguistic) are higher correlated while those which are dissimilar (such as economic and linguistic) are lower correlated (Puma, Lichtenstein, and Stein 2018; Harder et al. 2018; Phalet and Swyngedouw 2003). These results are in accordance with the literature where better integration in some aspects of the integration tend to 
be associated with better integration in other dimensions of integration (functionally related). As such, they can contribute to the ongoing debates on the modes of integration (assimilation/integration vs. segmented/transnational positions) with empirical evidences from emerging destinations (Phalet and Swyngedouw 2003; Harder et al. 2018; Nimmerfeldt, Schulze, and Taru 2011).

Figure 1: Scatter-plot matrix for the six dimensions of integration

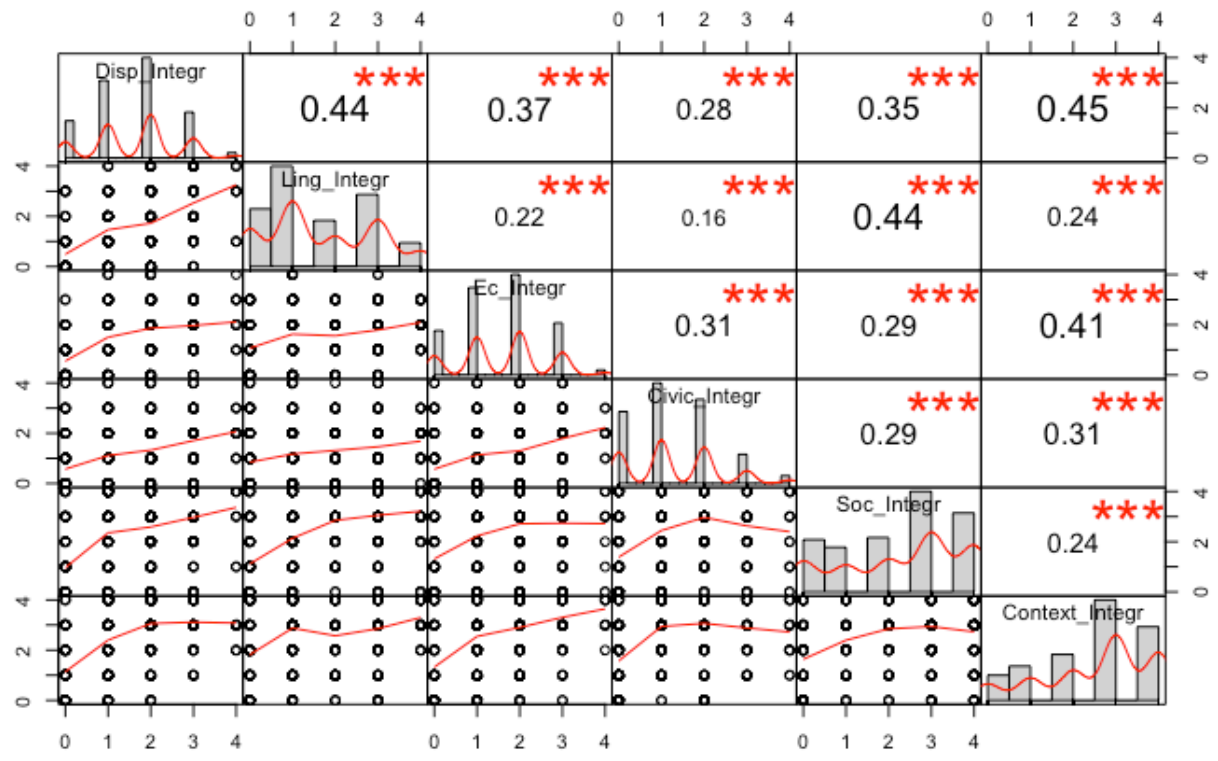

Note: The distribution of each variable is shown on panels in middle diagonal. Panels in the lower left display the bivariate scatter plots with a fitted line. Panels in upper right show the value of the correlation plus the significance level as stars. Each significance level is associated to a symbol: “***” means a p-values $<0.001$

Internal consistency was not measured within dimensions (i.e. for the 4 indicators which aggregate in one dimension) for a number of reasons. First, rather than being psychological constructs, the integration dimensions are counts of key behaviours which have an individualistic nature and are related to a particular aspect of integration. Second, as one of the main critics for Cronbach's alpha is the number of items included in the test, several studies 
have argued that 3-4 is not a large enough number of items to test for internal consistency. (Puma, Lichtenstein, and Stein 2018; Harder et al. 2018; OECD 2008: 26).

\section{Conclusions}

After several decades of intensive research, a consensus on how to define and assess immigrant integration is still missing. In the last several years numerous international efforts have been made to foster scientific progress in the field. Yet, immigrant integration in emerging destination countries remains particularly little studied despite several calls for more research on the topic. Studying immigrant integration in emerging destinations can be fruitful by providing evidences for public policies in emerging destinations which usually have limited experience in integrating migrants but also can help improving existent understanding of immigrant integration by offering a different view on how integration unfolds in societies with minimal institutional support.

Using data collected in 2018 as part of the IIIR research project, this article develops an integration framework based on 6 dimensions and 24 indicators of integration to assess the level of immigrant integration in an emerging destination. The 6 dimensions which compose the Integration Score are: dispositional, linguistic, economic, civic, social, and contextual. For each of the 6 dimensions, 4 indicators are used and a score between 0 and 4 can be assigned.

The Integration Score represents a proxy for immigrants' overall knowledge and capacity to build a successful life in emerging destinations. The undertaken statistical tests show that the developed Integration Score is correlated in the expected direction with two well-established predictors of immigrant integration: higher education $(B=2.345, P<0.05)$ and years of residency $(\mathrm{B}=0.069, \mathrm{P}<0.05)$; while it provided unexpected results for the legal status predictor $(B=-0.429, \mathrm{P}>0.05)$. The convergent-divergent validity points out that the direction and strength of correlations between the 6 dimensions is in accordance with findings in previous studies. In other words, higher correlation exists between theoretically related dimensions (e.g. dispositional and contextual, $\mathrm{r}=0.446, \mathrm{P}<0.0001$ ) and lower correlation between 
theoretically unrelated dimensions (e.g. civic integration and linguistic, $\mathrm{r}=$ $0.164, \mathrm{P}<0.0001)$. At the same time, the value of Cronbach's alpha coefficient $(\alpha=0.732)$ shows that all 6 dimensions significantly contributes with information to the Integration Score. As such, the results show that Integration Score is a statistically valid and internally consistent construct which can be used in the emerging destinations context to measure immigrant integration.

Besides presenting the outcomes on the construct validity and internal consistency tests, these results can also be seen as contribution to the ongoing debates on the modes of integration (assimilation/integration vs. segmented/transnational positions) by providing empirical evidences from emerging destinations which points towards an assimilation/integration position. The article also makes an important empirical contribution by providing evidences from emerging destinations to the literature where integration is understood as multidimensional concept by showing that the six dimensions taken into consideration have significant contributions to the Integration Score. Yet another important contribution to the literature is that the article shows how integration unfolds in societies with minimal institutional support by reporting that a legal status similar to the local population does not led to better integration outcomes as the literature suggests.

This article does not claim that this framew ork is the only one or the best measure of integration in emerging destinations. This article's goal was to develop an integration framework which can be empirically tested with data collected directly from immigrants from emerging destinations. The developed integration framework can be an opportunity for public institutions, NGOs, academics and other interested stakeholders to better document and quantify immigrant integration in emerging destinations and in turn provide improved integration policies.

This article has a number of limitations. Some of these limitations occur from the research design of the IIIR research project from where the data is taken and are related to the sample not being randomly selected. Another limitation of this study is that it focused its integration framework only on the immigrants' perspective and did not provide data about the receiving societies. This conflicts with one of the current prevalent views on immigrant 
integration where integration is seen as a bi-directional process which affects both immigrants and the receiving society. Future research working with both immigrants and the receiving society perspective on integration could be a valuable contribution to the field. In this study the unit of analysis is the individual, yet several studies highlighted that integration can be better understood when analysing families. Future research working with families as unit of analysis could provide better understanding of this complex phenomenon. Another important limitation is that in this study the internal consistency within integration dimesons was not measured within dimensions due to the nature of the dimensions (rather behavioural than psychological constructs) and the small number of items $(\mathrm{N}=4)$ which compose each dimension.

\section{Acknowledgements}

This article was written as part of the Romanian Immigrant Index research project co-financed as part of the 'Romanian Centre for Migration Research' Project which was co-financed through the Asylum, Migration and Integration Fund (AMIF) - ID: FAMI/16.01.01. This work was also partially supported by a grant of the Romanian Ministry of Research and Innovation, CNCS - UEFISCDI, project number PN- III- P1- 1.1- BSH- 2- 2016- 0005, within PNCDI III. The funders had no role in study design, data collection and analysis, decision to publish, or preparation of the manuscript. Scholars who have commented on earlier versions of this paper include Remus Gabriel Anghel, Alin Croitoru, Bogdan Voicu, and Toma Burean. The article was presented and received feedback and comments during the: a) Workshop on Immigrants' Integration in New Destination Countries, held in Cluj-Napoca, 10-11 of May 2018; b) the International Summer School and workshop on 'Migration and Integration', Cluj-Napoca, Romania, July 13-20, 2018. 


\section{Bibliography}

Abdou, Leila Hadj. 2019. 'Immigrant Integration: The Governance of EthnoCultural Differences.' Comparative Migration Studies 7 (15): 1-8.

Ager, Alastair, and Alison Strang. 2008a. 'Understanding Integration: A Conceptual Framework.' Journal of Refugee Studies. https://doi.org/10.1093/jrs/fen016.

- - . 2008b. 'Understanding Integration: A Conceptual Framework.' Journal of Refugee Studies 21 (2): 166-91. https://doi.org/10.1093/jrs/fen016.

Aleksynska, Mariya, and Yann Algan. 2010. 'Assimilation and Integration of Immigrants in Europe.' Institute for the Study of Labor (IZA). http://www.econstor.eu/handle/10419/46025\%5Cnhttp:/ /ideas.re pec.org/p/iza/izadps/dp5185.html.

Anghel, Remus Gabriel, Alina Botezat, Anatolie Cosciug, Ioana Manafi, and Monica Roman. 2016. 'International Migration, Return Migration, and Their Effects: A Comprehensive Review on the Romanian Case.' IZA DP No. 10445. DISCUSSION PAPER SERIES. Bonn.

Bauböck, Rainer, and Milena Tripkovic. 2017. The Integration of Migrants and Refugees. An EUI Forum on Migration, Citizenship and Demography. European University Institute. https:/ / doi.org/10.2870/30835.

Beversluis, David, David Schoeller-Diaz, Martin Anderson, Natalie Anderson, Amy Slaughter, and Ronak B. Patel. 2017. 'Developing and Validating the Refugee Integration Scale in Nairobi, Kenya.' Journal of Refugee Studies 30 (1): 106-32. https:/ / doi.org/10.1093/jrs/few018.

Bijl, Rob, and Arjen Verweij. 2012. 'Measuring and Monitoring Immigrant Integration in Europe.'

Borsboom, Denny, Gideon J. Mellenbergh, and Jaap Van Heerden. 2004. “The Concept of Validity.' Psychological Review 111 (4): 1061-71. https://doi.org/10.1037/0033-295X.111.4.1061.

Brown, Carrie M., Andre Peri, and Sara Garrow Ruebelt. 2011. 'Development and Validation of a Pre-Migration Acculturation Measure.' Interamerican Journal of Psychology $45 \quad$ (2): 305-12. https://doi.org/10.30849/rip/ijp.v45i2.160.

Castles, Stephen, Maja Korac, Ellie Vasta, Steven Vertovec, Katrin Hansing, Fiona Moore, Emma Newcombe, Lucy Rix, and Soojin Yu. 2002. 
“Integration: Mapping the Field.' Immigration Research and Statistics Service. London.

Coșciug, Anatolie. 2019. 'Religion, Return Migration and Change in an Emigration Country.' In Transnational Return and Social Change, edited by Remus Gabriel Anghel, Margit Fauser, and Paolo Boccagni, 85-102. London/New York: ANTHEM PRESS. http://www.anthempress.com/index.php/transnational-returnand-social-change-hb.

Cos,ciug, Anatolie, Ionela Racăaŭ, Gabriel Bădescu, Toma Burean, Georgiana Gărus, Carmen Greab, Bogdan Radu, Calin Rus, and Andreea Vornicu. 2018. “Indexul Integrării Imigranților În România.' ClujNapoca.

Council of Europe. 1997. 'Measurement and Indicators of Integration.' Directorate of Social and Economic Affairs. www.coe.int/t/dg3/migration/.../Measurement_indicators_integrat ion_en.pdf.

Croitoru, Alin, Dumitru Sandu, and Elena Tudor. 2014. 'The Europeanisation of Everyday Life: Cross-Border Practices and Transnational Identifications Among EU and Third-Country Citizens Romanians ' Social Transnationalism in the Making.'

Drăgan, Elena, Luciana Lăzărescu, Victoria Nedelciuc, Ovidiu Voicu, Daniela Tarnovschi, Andrei Adamecz, and Elena Drăgan. 2014. "Study on the Opinions and Perceptions of Population on Immigrant Integration.' Bucharest.

Drbohlav, Dušan, and Dagmar Dzúrová. 2007. "'Where Are They Going?": Immigrant Inclusion in the Czech Republic (A Case Study on Ukrainians, Vietnamese, and Armenians in Prague).' International Migration 45 (2): 69-95. https://doi.org/10.1111/j.14682435.2007.00404.x.

Ersanilli, Evelyn, and Ruud Koopmans. 2013. 'The Six Country Immigrant Integration Comparative Survey (SCIICS): Technical Report.' Berlin.

EUROSTAT. 2019. "Population and Population Change Statistics - Statistics Explained.' Brussels. http://ec.europa.eu/eurostat/statisticsexplained/index.php/Population_and_population_change_statistics \%0Ahttp://epp.eurostat.ec.europa.eu/statisticsexplained/. 
Faist, Thomas. 2000. 'Transnationalization in International Migration: Implications for the Study of Citizenship and Culture.' Ethnic and Racial Studies 23: 189-222. http://www.ingentaconnect.com.proxyau.wrlc.org/content/routled $\mathrm{g} / \mathrm{rers} / 2000 / 00000023 / 00000002 /$ art00001.

Favell, Adrian. 2003. 'Integration Nations: The Nation-State and Research on Immigrants in Western Europe.' In Comparative Social Research, 13-42. https://doi.org/10.1016/S0195-6310(03)22001-9.

Garcés-Mascareñas, Blanca, and Rinus Penninx. 2016. 'Integration Processes and Policies in Europe. Contexts, Levels and Actors. 'Edited by Blanca Garcés-Mascareñas and Rinus Penninx. Integration Processes and Policies in Europe, IMISCOE Research Series. Springer. https://doi.org/978-3-319-21673-7.

Grzymała-Kazłowska, Aleksandra. 2015. 'The Role of Different Forms of Bridging Capital for Immigrant Adaptation and Upward Mobility. The Case of Ukrainian and Vietnamese Immigrants Settled in Poland.' Ethnicities 15 (3): 460-90. https:/ / doi.org/10.1177/1468796813518314.

Harder, Niklas, Lucila Figueroa, Rachel M. Gillum, Dominik Hangartner, David D. Laitin, and Jens Hainmueller. 2018. 'Multidimensional Measure of Immigrant Integration.' Proceedings of the National Academy $\begin{array}{lllll}\text { of } & \text { Sciences } & 115 & \text { (45): }\end{array}$

https://doi.org/10.1073/pnas.1808793115.

Huddleston, Thomas, Özge Bilgili, Anne-Linde Joki, and Zvezda Vankova. 2015. 'Migrant Integration Policy Index 2015.' Barcelona/ Brussels. http://www.mipex.eu/download-pdf\#/add-selection.

Huddleston, Thomas, Jan Niessen, and Jasper Dag Tjaden. 2013. 'Using EU Indicators of Inmigrant Integration.' Brussels. https://doi.org/10.2837/34091.

Jimenez, Tomas. 2011. 'Immigrants in the United States: How Well Are They Integrating into Society?' Washington, DC: Migration Policy Institute.

Klarenbeek, Lea M. 2019. 'Relational Integration: A Response to Willem Schinkel.' Comparative Migration Studies 7 https://doi.org/10.1186/s40878-019-0126-6.

Levitz, Philip, and Grigore Pop-Eleches. 2010. “Monitoring, Money And Migrants: Countering Post-Accession Backsliding in Bulgaria And 
Romania.' Europe - Asia Studies $62 \quad$ (3): 461-79. https://doi.org/10.1080/09668131003647838.

Lichtenstein, Gary, and Jini E Puma. 2018. 'The Refugee Integration Survey and Evaluation (RISE): Results from a Four-Year Longitudinal Study.' Journal of Refugee Studies, no. August. https://doi.org/10.1093/jrs/fey034.

Lindstrom, David P. 2016. 'How Representative Are Snowball Samples? Using the Ethnosurvey to Study Guatemala-U.S. Migration.' Annals of the American Academy of Political and Social Science 666 (1): 64-76. https://doi.org/10.1177/0002716216646568.

Loch, Dietmar. 2014. "Integration as a Sociological Concept and National Model for Immigrants: Scope and Limits.' Identities 21 (6): 623-32. https://doi.org/10.1080/1070289X.2014.908776.

Lomba, Sylvie da. 2010. 'Legal Status and Refugee Integration: A UK Perspective.' Journal of Refugee Studies 23 (4): 415-36. https://doi.org/10.1093/jrs/feq039.

Maria de Paola; Giorgio Brunello. 2016. 'Education as a Tool for the Economic Integration of Migrants.' Journal of Chemical Information and Modeling 53 (9836): 58. https:/ / doi.org/10.1017/CBO9781107415324.004.

McKenzie, David J., and Johan Mistiaen. 2009. 'Surveying Migrant Households: A Comparison of Census-Based, Snowball and Intercept Point Surveys.' Journal of the Royal Statistical Society. Series A: Statistics in Society 172 (2): 339-60. https://doi.org/10.1111/j.1467985X.2009.00584.x.

Messina, Anthony M., and Abigail Fisher Williamson. 2014. 'Introduction. Dimensions of Variation in Newly Diverse Transatlantic Destinations.' In .

Migration Policy Group/Institute of Public Affairs. 2019. 'The European Benchmark for Refugee Integration: A COMPARATIVE ANALYSIS OF THE NATIONAL INTEGRATION EVALUATION MECHANISM IN 14 EU COUNTRIES.' Brussels/Warsaw.

NIEM. 2019. Asylum Seekers and Beneficiaries of International Protection in V4 Countries.

Nimmerfeldt, Gerli, Jennie Schulze, and Marti Taru. 2011. 'The Relationship between Integration Dimensions among Second Generation Russians 
in Estonia.' Studies of Transition States and Societies 3 (1): 76-91.

OECD/EU. 2015. 'Indicators of Immigrant Integration 2015. SETTLING IN.' Paris/Brussels. https://doi.org/10.1787/9789264234024-en.

- - . 2018. Settling in 2018: Indicators of Immigrant Integration. Paris/Brussels: OECD Publishing/European Union,.

OECD. 2008. Handbook on Constructing Composite Indicators: Methodology and User Guide. Paris: OECD Publishing. https://doi.org/10.1787/9789264043466-en.

Penninx, Rinus. 2019. 'Problems of and Solutions for the Study of Immigrant Integration.' Comparative Migration Studies 7 https://doi.org/10.1186/s40878-019-0122-x.

Phalet, Karen, and Marc Swyngedouw. 2003. 'Measuring Immigrant Integration: The Case of Belgium.' Studi Emigrazione XL (152): 773-804.

Puma, Jini E., Gary Lichtenstein, and Paul Stein. 2018. 'The RISE Survey: Developing and Implementing a Valid and Reliable Quantitative Measure of Refugee Integration in the United States.' Journal of Refugee Studies 31 (4): 605-25. https:/ / doi.org/10.1093/jrs/fex047.

Reichel, David, and Laura Morales. 2017. "Surveying Immigrants without Sampling Frames - Evaluating the Success of Alternative Field Methods.' Comparative Migration Studies 5 (1): 1-22. https://doi.org/10.1186/s40878-016-0044-9.

Roots, Ave, Anu Masso, and Mare Ainsaar. 2016. 'Measuring Attitudes towards Immigrants: Validation of Immigration Attitude Index Across Countries.' Lausanne.

Saharso, Sawitri. 2019. 'Who Needs Integration? Debating a Central, yet Increasingly Contested Concept in Migration Studies.' Comparative Migration Studies 7 (1): 16-18. https://doi.org/10.1186/s40878-0190123-9.

Schinkel, Willem. 2018. 'Against 'Immigrant Integration': For an End to Neocolonial Knowledge Production.' Comparative Migration Studies 6 (1): 1-17. https:/ / doi.org/10.1186/s40878-018-0095-1.

Schlueter, Elmar, Bart Meuleman, and Eldad Davidov. 2013. 'Immigrant Integration Policies and Perceived Group Threat: A Multilevel Study of 27 Western and Eastern European Countries.' Social Science Research 42 (3): 670-82. https:/ / doi.org/10.1016/j.ssresearch.2012.12.001. 
Schneider, Jens, and Maurice Crul. 2010. 'New Insights into Assimilation and Integration Theory: Introduction to the Special Issue.' Ethnic and Racial Studies 33 (7): 1143-48. https:/ / doi.org/10.1080/01419871003777809.

Smith, Gregory T. 2005. 'On Construct Validity: Issues of Method and Measurement.' Psychological Assessment 17 (4): 396-408. https://doi.org/10.1037/1040-3590.17.4.396.

Stefańska, Renata. 2015. 'Integration Policy and Activities in Poland, INTERACT Research Report 2015/07.'

United Nations. 2017. International Migration Report 2017. Highlights. New York.

Voicu, Ovidiu, Andra Bucur, Victoria Cojocariu, Luciana Lăzărescu, Marana Matei, and Daniela Tarnovschi. 2015a. 'Barometrul Integrării Imigranților. Ediția 2015. Raport Final de Cercetare.' București. http://www.cdcdi.ro/files/services/19_0_BII 2015 final 2015.pdf.

- - - . 2015b. “EDIȚIA 2015 Raport Final de Cercetare.'

Wachter, Gusta G., and Fenella Fleischmann. 2018. 'Settlement Intentions and Immigrant Integration: The Case of Recently Arrived EU-Immigrants in the Netherlands.' International Migration 56 (4): 154-71. https://doi.org/10.1111/imig.12434. 